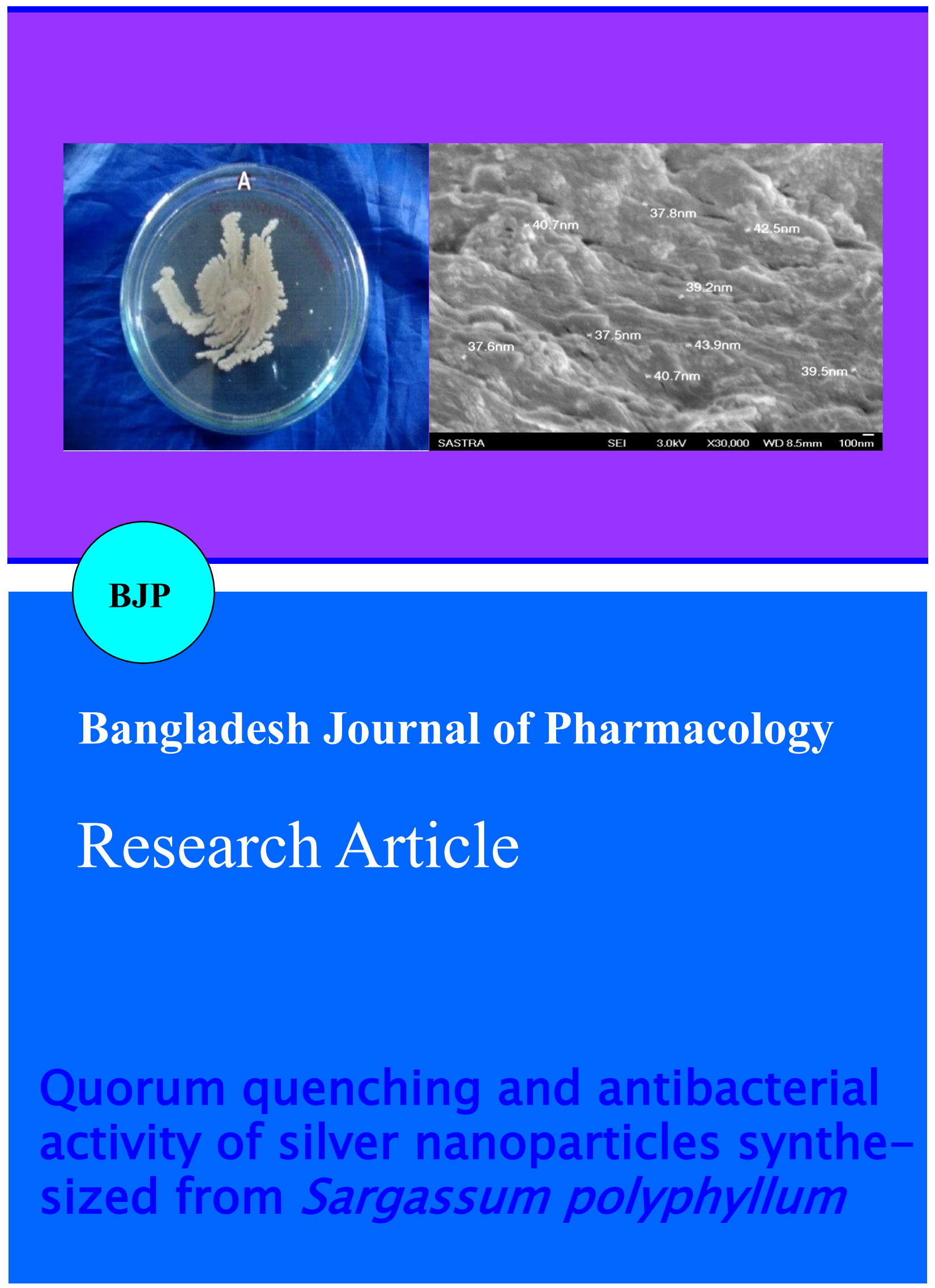




\title{
Quorum quenching and antibacterial activity of silver nanoparticles synthesized from Sargassum polyphyllum
}

\author{
Mani Arunkumar'1, Karuppaiyan Suhashini' ${ }^{1}$, Narayanan Mahesh¹ and Raju Ravikumar² \\ ${ }^{1}$ Department of Chemistry and Biosciences, Srinivasa Ramanujan Centre, SASTRA University, Kumbakonam, Tamil \\ Nadu 612 001, India; ' School of Chemical and Biotechnology, SASTRA University, Thanjavur, Tamil Nadu 613402, \\ India.
}

\begin{tabular}{|c|c|}
\hline \multicolumn{2}{|l|}{ Article Info } \\
\hline Received: & 15 December 2013 \\
\hline Accepted: & 2 January 2014 \\
\hline Available Online: & 3 February 2014 \\
\hline \multicolumn{2}{|c|}{ DOI: 10.3329/bjp.v9i1.17301 } \\
\hline \multicolumn{2}{|c|}{$\begin{array}{l}\text { Cite this article: } \\
\text { Arunkumar M, Suhashini K, Mahesh } \\
\mathrm{N} \text {, Ravikumar R. Quorum quenching } \\
\text { and antibacterial activity of silver } \\
\text { nanoparticles synthesized from Sar- } \\
\text { gassum polyphyllum. Bangladesh J } \\
\text { Pharmacol. 2014; } 9: 54-59 \text {. }\end{array}$} \\
\hline
\end{tabular}

\begin{abstract}
Development of efficient methodology for the green synthesis of silver nanoparticles using marine algae is a modern area of research in the field of phyconanotechnology. In this regard, the present study deals with green synthesis of silver nanoparticles (AgNPs) by using aqueous extracts of marine brown seaweed Sargassum polyphyllum. UV-visible spectral analysis reveals the formation of AgNPs by showing absorption maximum at $420 \mathrm{~nm}$ wavelength and SEM analysis clearly elucidate the polydispersed structure of AgNPs without aggregation and ranged in size from $37-43 \mathrm{~nm}$. X-ray Diffraction pattern confirmed the AgNPs crystalline personality. The synthesized AgNPs showed more enduring antibacterial activity against test bacterial pathogens. Furthermore, the synthesized AgNPs exhibited varying level of inhibition of violacein production and swarming motility. In the near future, silver nanoparticles can be extremely useful in clinical medicine as an alternative method for the treatment of wound infection.
\end{abstract}

\section{Introduction}

Biological synthesis of nanoparticles using marine seaweeds has received much attention because of their potential to synthesize nanoparticles of various size, shape and morphology. Modern nanotechnology is greatly used for enhancing the properties of materials (Smith et al., 2006) and also applied to develop new nanodevices especially for the diagnosis of cancer (Ahmad et al., 2002; Huang et al., 2004). Among all the nanoparticles exploited, silver nanoparticles (AgNPs) are nanometal: Spherical in shape, and ranges from 12.5 to $100 \mathrm{~nm}$ in size able to acts on a wide range of target sites (Ahmad et al., 2003). Moreover, AgNPs comprises great number of applications including high-sensitivity biomolecular detection, diagnostics, pharmaceuticals, anti bacterial, antiquorum sensing, antifungal, and antiplasmodial properties etc. (Asmathunisha et al., 2010; Thirumurugan et al., 2010).
In past few decades, several amount of antibiotics used for the treatment of human diseases; resulted to create many pathogenic bacteria resistant to multiple drugs. Now-a-days, the multidrug resistance bacteria are developed due to the bacterial transposons occur on resistance (R) plasmids and also over expression of gene that code for multidrug efflux pumps. In recent years, multidrug resistant bacteria are increasingly held responsible for wound infection and have become a serious public health issue, which raised the need to develop new bactericidal materials (Nikaido, 2009). Many researcher have clearly noted that these bacteria capable of communicating within themselves with the help of quorum sensing molecule and establishes there infection rapidly in human for its survivability. Most of gram-positive and gram-negative bacteria capable of producing small molecules called autoinducers to communicate each other on when threshold number of same bacterial species are present. This molecules 
directly or indirectly induce the virulent factors of bacteria thereby make the bacteria to survive any environmental stress (Vattem et al., 2008). In $P$. aeruginosa PAO1, the expression of all virulent factors was controlled by quorum sensing system. Several attempts were made to develop a molecule or enzyme which interfere the quorum sensing system of this pathogen, thereby it may prevent the biofilms formation which are more susceptible to conventional antibio -tics. This makes quorum sensing a very attractive target for the development of an anti-infective therapy (David et al., 2002).

In most literature survey the AgNPs show inhibitory and bactericidal activity against wide range of microorganism. Biological synthesis of silver nanoparticles using bacteria, fungi, algae, enzymes and plant extracts is ecofriendly, time conception and able to synthesis different sizes and shapes of stable nanocolloids (Gnanadesigan et al., 2012). Moreover synthesis of AgNPs using marine brown algae shows more advantageous over other biological processes because it reduce the cell maintaining process, easy to harvest and also extremely suitable for large scale production of silver nanoparticles (Singh et al., 2013). The purpose of the present work was to determine the quorum quenching and antibacterial activity of AgNPs synthesized from marine seaweed Sargassum polyphyllum, thereby throwing light on the potential role of algae in increasing the effectiveness of antibiotics.

\section{Materials and Methods}

Chemicals: Silver nitrate (purity $>99.99 \%$, Aldrich), Nacyl homoserine lactone (AHL) and Mueller-Hinton agar is obtained from sigma Aldrich. All the glassware were washed thrice with deionised water and dried in oven before use. The other chemicals and reagents where used in these study were of analytical grade.

Bacterial strains: The human bacterial pathogens responsible for wound infection such as Staphylococcus aureus MTCC 3160, Escherichia coli MTCC 1722, Bacillus subtilis MTCC 2387, and Pseudomonas aeruginosa MTCC 2488 were procured from Microbial Type Culture Collection, Institute of Microbial Technology (IMTECH), and Chan -digarh, India. The bioindicator strain Chromobacterium violaceum $\mathrm{CV} 026$ is a mini-Tn5 mutant derived from $C$. violaceum MTCC 2656. C. violaceum CV026, a mutant of the saprophytic bacterium that is unable to produce the purple pigment violacein unless exogenous AHLs are supplied, was used as a reporter organism to test for Quorum Sensing Inhibition (QSI).

Sample collection: Marine brown seaweed samples such as S. polyphyllum were collected by hand picking method at depth of 1-2 meter in south East coast of India, Mandapam (Lat $9^{\circ} 45^{\prime} \mathrm{N}$; Long $79^{\circ} 15^{\prime} \mathrm{E}$ ), and Tamil Nadu. The collected seaweeds were identified from
Marine Algal Research Station, Cenual salt and Marine Chemicals Research Institute, Mandapam. The collected seaweeds were washed with seawater to remove the dust and soil. The cleaned samples were preserved in a clean zip lock polythene bags. The bags were stored under refrigeration at $4^{\circ} \mathrm{C}$ for further process. The seaweed is identified and shade dried for 15 days and powdered using mixer grinder.

Preparation of seaweed extracts: Frozen seaweed samples (10 g) were grinded using a mortar and pestle, and then extracted by incubation for $30 \mathrm{~min}$ with $100 \mathrm{~mL}$ distilled water by heating at $70^{\circ} \mathrm{C}$. The extract was filtered using Whatmann No.1 filter paper and refrigerated at $4^{\circ} \mathrm{C}$ until further analysis.

Phytochemical analysis: A fraction of seaweed extracts was subjected to phytochemical screening as described by Harborne, 1998. Natural chemical groups such as Aminoacids, alkaloids, carbohydrates, Flavonoids, sapo -nins, sterols, tannins, Terpenoids, proteins and phenollic compounds were probed.

Silver nanoparticles synthesis using seaweeds: $10 \mathrm{~mL}$ of aqueous extracts of $S$. polyphyllum (10 g sample in 100 $\mathrm{mL}$ distilled water) solution was added to $90 \mathrm{~mL}(1 \mathrm{mM}$ silver nitrate, AR grade) to makeup final volume to 100 $\mathrm{ml}$. The solution was exposed to a range of controlled temperatures varying from $25-37^{\circ} \mathrm{C}$, with continuous agitation at $100 \mathrm{rpm}$ for 24 hours and monitored for the formation of AgNPs. The change in color from colorless to brown color was taken for visible confirmation of silver nanoparticles.

$U V$-visible spectroscopy: The bioreduction of silver ions was monitored by ultraviolet-visible (UV-vis) absorption measurement using PerkinElmers LAMBDA 45 spectrophotometer. The formation of silver nanoparticles was observed at multiple time intervals from 0-24 hours. The absorption spectrum was analysed in 200$600 \mathrm{~nm}$ ranges.

Scanning electron microscopy: The seaweeds mediated synthesized AgNPs were subjected to lyophilization using VirTis benchtop machine. After lyophilization, the purified AgNPs size, shape, and arrangement pattern were analysed by using SEM.

$X$-ray diffraction (XRD) measurements: The crystalline structure and diffraction pattern of seaweed mediated AgNPs were analysed using XRD. For X-ray diffraction measurements, the hydrosol of the AgNPs was purified by repeated centrifugation. After freeze drying, the structural analysis of the dried sample was done with an $X^{\prime}$ pertpro X-ray diffractometer (D8 Focus Bruker) operated at $40 \mathrm{kV}$ and $30 \mathrm{~mA}$ with $\mathrm{Cu} \mathrm{K} \infty$ radiation.

Antibacterial activity of AgNPs: In vitro antibacterial activity assay was carried out by using Kirby-Bauer method. The disc diffusion method was used to screen out the antimicrobial activity of AgNPs by using Muller Hinton Agar (MHA). $15 \mathrm{~mL}$ of MHA were prepared 
and poured into sterile petri plates and then allowed to solidify for $5 \mathrm{~min}$. The four different bacterial pathogenic microorganisms such as $S$. aureus, E. coli, $P$. aeruginosa and $B$. subtilis were spreaded uniformly on the surface of a Muller Hinton agar (MHA) plate at a concentration of $10^{5}$ to $10^{6} \mathrm{CFU} / \mathrm{mL}$. The different concentration of AgNPs (5, 10, 15, $20 \mu \mathrm{L} /$ disc) were loaded on $6 \mathrm{~mm}$ sterile disc and incubated at $37^{\circ} \mathrm{C}$ for 24 hours. After the period of incubation, inhibition zones formed around the disc were measured using high antibiotic zone scale.

In vitro bioassay for quorum quenching activity: In vitro bioassay for quorum quenching activity using Chromobacterium violaceum quorum sensing system was performed by well diffusion methods according to Mc clean et al., 1997. C. violaceum CVO26 strain used for determining pigment inhibition activity by seaweed mediated silver nanoparticles. The log phase of $C$. violaceum CVO26 approximately $\left(2.5 \times 10^{6} \mathrm{CFU} / \mathrm{mL}\right)$ were aseptically transfer to the Luria agar plates along with $30 \mu \mathrm{g}$ of AHLs as exogenous source of quorum sensing molecules and made well of (3 mm diameter) impregnated with different concentration $(10,15,20) \mu \mathrm{L}$ of silver nanoparticles. Then the plates were incubated overnight at $30^{\circ} \mathrm{C}$ and QS inhibition was detected as a colourless zone around the well. The inhibition of violacein pigment by AgNPs indicates the quorum quenching activity of nanocolloids.

Swarming assay: The swarming assay of $P$. aeruginosa was investigated using the following media composition: $0.5 \%$ Bacto agar, $0.8 \%$ nutrient broth and $1.0 \%$ glucose. The sterilized media was allowed to pour in the sterile petri plate along with different sub-inhibitory concentration $(5,10,15,20 \mu \mathrm{L})$ of silver nanoparticles and allowed to absorb for 3-4 hours at $37^{\circ} \mathrm{C}$ (Shrout et al., 2006). Five microliters of $P$. aeruginosa culture was aseptically transfer to the centre of the agar surface and incubated for $20-24$ hours at $37^{\circ} \mathrm{C}$. Extent of swarming motility and distribution pattern of colony morphology was examined after the period of incubation.

\section{Results and Discussion}

The phytochemical characteristics of aqueous extracts of S. polyphyllum investigated are summarized in Table I. The results revealed the presence of medicinally active constituents like of alkaloids, tannins, saponins, phlobatannins, flavonoids, terpenoids, glycosides and, steroids in the aqueous extracts of S. polyphyllum.

The primary study was conducted to screen marine brown seaweeds $S$. polyphyllum for the synthesis of AgNPs. Aqueous $\mathrm{Ag}^{+}$ions were reduced to AgNPs when it is exposed to extract of S. polyphyllum. Moreover, addition of $S$. polyphyllum extract to $1 \mathrm{mM}$ aqueous $\mathrm{AgNo}_{3}$ solution lead to the appearance of yellowish brown color indicating the formation of silver nanoparticles with in 1 hour and these nanoparticles were stable for several weeks (Figure 1). However, no change in color was observed in the control set. The change of color from colorless to yellowish dark brown after the $1 \mathrm{~h}$ of incubation is due to the excitation of free electrons in the reaction mixture (Prasad et al., 2011).

UV-vis absorption spectra are known to be quite sensitive to the formation of AgNPs. Thus the formation of AgNPs was monitored by visual inspection of

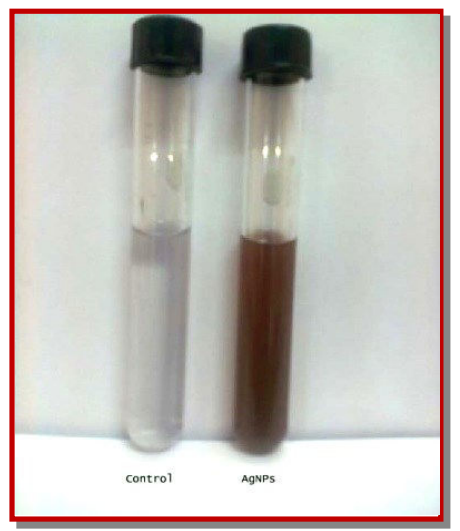

Figure 1: Biosynthesis of AgNPs using marine seaweed Sargassum polyphyllum

the solution. A UV-vis spectrum is one of the most important techniques provided surface plasmon resonance exists for the metal. UV-vis absorption spectra for AgNPs prepared using cell free extract were obtained at multiple time intervals from the beginning of the bioreductive reaction. Maximum absorption spectrum in the range of 200-600 nm was determined by UV-vis spectroscopy and it was found to be $420 \mathrm{~nm}$ for the seaweeds mediated AgNPs (Figure 2). The spectra resulting from the excitation of Surface Plasmon Resonance (SPR) due to the reduction of $1 \mathrm{mM}$ silver

\begin{tabular}{|c|c|c|}
\hline \multicolumn{3}{|c|}{ Table I } \\
\hline \multicolumn{3}{|c|}{ Phytochemical constituents of the marine } \\
\hline & seaweed Sargassum polyphyllum \\
\hline SL. & Chemical constitu- & Aqueous extracts of Sargas- \\
No. & ent & sum polyphyllum \\
\hline 1 & Alkaloids & Present \\
2 & Tannins & Present \\
3 & Saponins & Present \\
4 & Phlobatannins & Absent \\
5 & Flavanoid & Present \\
6 & Terpenoid & Present \\
7 & Glycosides & Absent \\
8 & Steroid & Present \\
\hline
\end{tabular}

ions in the extract (Sharma et al., 2009).

The representative scanning electron microscopic image recorded from the AgNPs indicating that the AgNPs are formed extracellularly by the reduction of silver ions. SEM analysis reveals the size and structural 


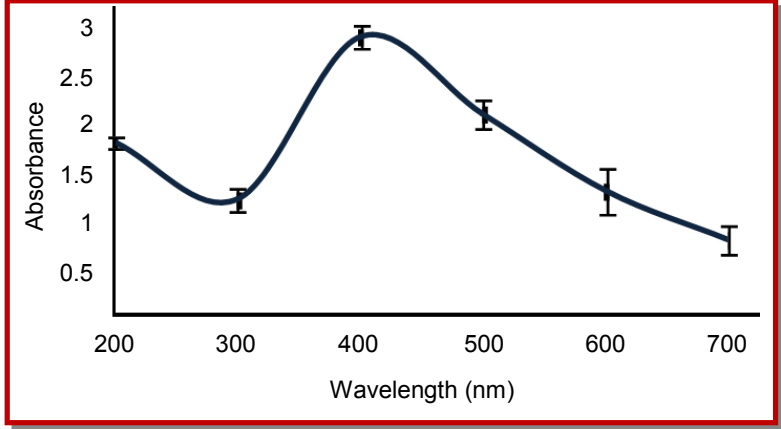

Figure 2: UV-visible absorption spectra of silver nanoparticles synthesized from Sargassum polyphyllum. Values are the mean of $\mathrm{n}$ $=3($ mean \pm Standard error $)$

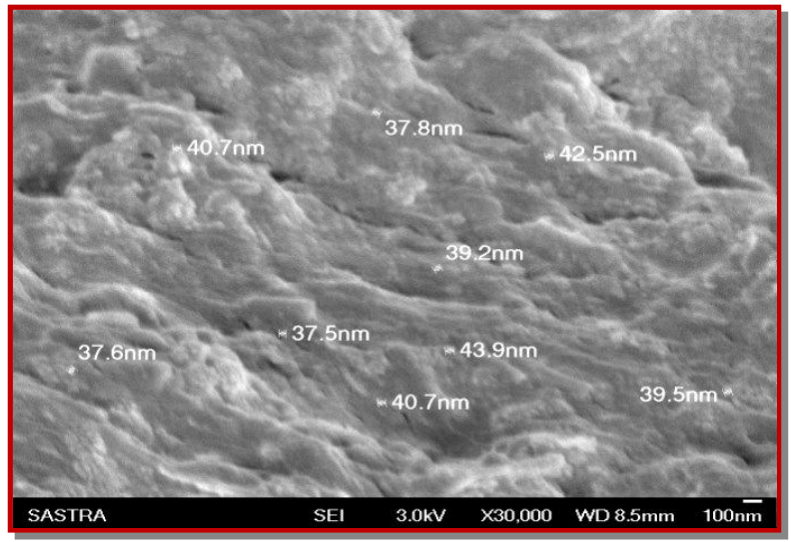

Figure 3: SEM image of AgNPs synthesized from Sargassum polyphyllum

patterns of silver nanocolloids. Moreover, the SEM micrographs of nanoparticles obtained in the prepared sample showed that the diameter of the nanoparticles in the above $37-43 \mathrm{~nm}$ (Figure 3). The silver nanoparticles are spherical in shape and well distributed with aggregations. We have observed that particles tend to stick on the surface and form agglomerates. Particles size and distribution from a biological synthesis are depend upon the nature of the microbial culture, concentration of the algal cell culture, growth process, as well as the extent of agglomeration (Jolocam Mbabazi et al., 2011).

The crystalline pattern of synthesized AgNPs was confirmed by XRD spectrum. The $2 \theta$ values of the XRD pattern was ranging from 10 to $60^{\circ}$ and three strong peaks were observed at $27.2^{\circ}, 36.0^{\circ}$ and $53.5^{\circ}$ were corresponded to the planes (275), (91.9) and (91.5) respectively (Figure 4). Nanoparticles XRD pattern exhibit several size-dependent features leading to anomalous peak positions, heights and widths (Jain et al., 2009). All the peaks in XRD pattern can be readily indexed to a face-centered cubic structure of silver as per available literature (JCPDS, File no: 4-0783) (Klug et al., 1954).

The in vitro antibacterial activity of $S$. polyphyllum mediated AgNPs was tested against human pathogenic bacteria such as $S$. aureus, $P$. aeruginosa, B. subtilis and $E$. coli using disk diffusion method. The $18 \mathrm{~mm}$ clear inhibitory zone appeared around $20 \mu \mathrm{L}$ AgNPs against E. coli after incubation for 24 hours followed by $P$. aeruginosa $(16 \mathrm{~mm})$, B. subtilis $(14 \mathrm{~mm})$ and $S$. aureus $(13$ $\mathrm{mm})$ suggesting that synthesized AgNPs showed phenomenon bactericidal effect (Table II). The real mechanism of the bactericidal effect of AgNPs is not

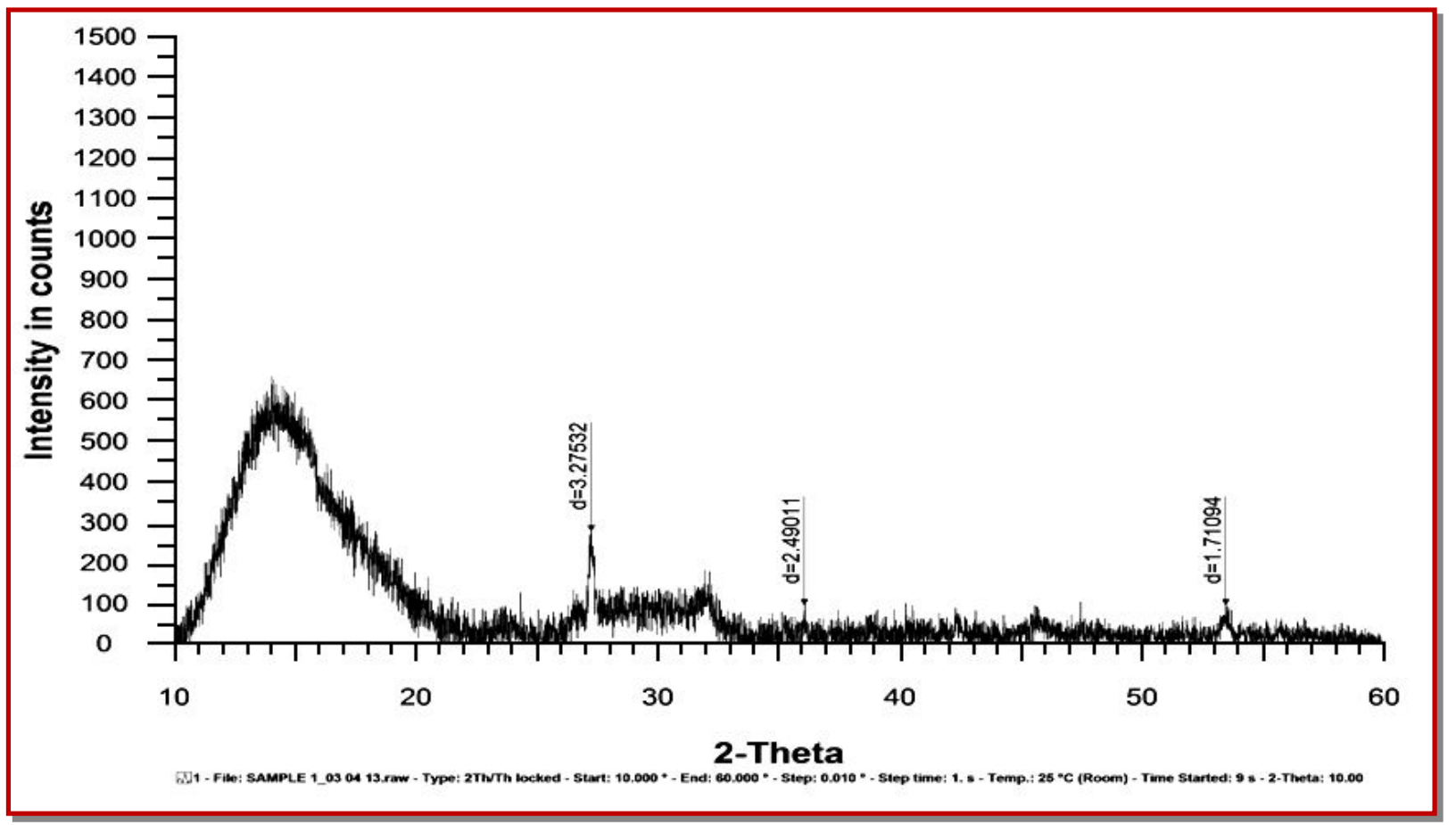

Figure 4: X-ray diffraction pattern of AgNPs synthesized by marine seaweed Sargassum polyphyllum 


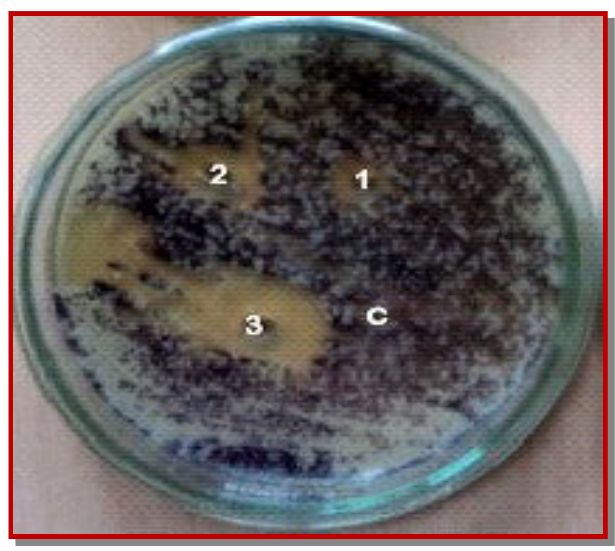

Figure 5: Bioassay for anti-quorum sensing activity of AgNPs Well of $3 \mathrm{~mm}$ diameter impregnated with different concentration $(5,10$, $15 \mu \mathrm{L}$ ) of AgNPs
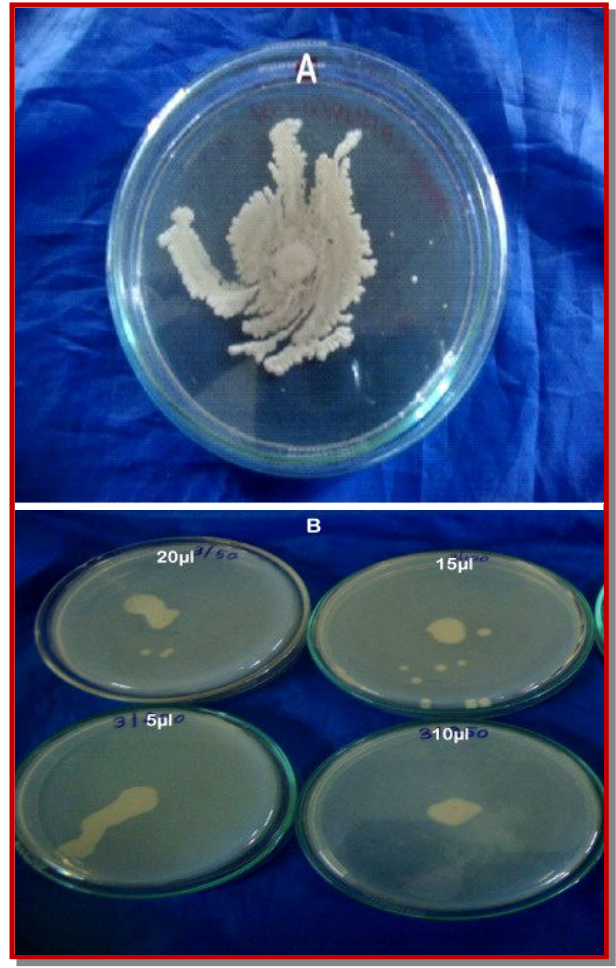

Figure 6: Swarming assay

Swarming motility is dependent upon the agar\% and concentrations of AgNPs. (A) Control (Without AgNPs)-unorganized swarming. (B) Different concentrations $(5,10,15,20 \mu \mathrm{L})$ of AgNPs

clearly elucidated but it may be due penetration of AgNPs into the bacterial cell thereby it inhibit the cellular proteins, inactive the enzyme, generating hydrogen peroxide and caused bacterial cell death. Moreover, it is also believed that the small surface area containing nanoparticles having interaction like large surface area it may attach with the cell membrane of the bacteria and involves the process of upsetting the respiration and permeability (Kyang Huwan et al., 2005). The adsorption on bacterial surface and

\begin{tabular}{|cccccc|}
\hline \multicolumn{5}{|c|}{ Table II } \\
\hline \multicolumn{5}{|c|}{ Antibacterial activity of AgNPs } \\
\hline SL. & Pathogenic bac- & \multicolumn{5}{c|}{ Zone of inhibitions (mm) } \\
\cline { 2 - 6 } No. & teria & $5 \mu \mathrm{L}$ & $10 \mu \mathrm{L}$ & $15 \mu \mathrm{L}$ & $20 \mu \mathrm{L}$ \\
& & 4 & 6 & 9 & 13 \\
1 & S. aureus & 6 & 7 & 11 & 17 \\
2 & P. aeruginosa & 5 & 8 & 12 & 14 \\
3 & B. subtilis & 7 & 9 & 14 & 18 \\
4 & E. coli & & & \\
& &
\end{tabular}

intracellular enzyme activity is the main reason for the antibacterial reactions (Rajesh Kumar et al., 2012). Nowa-days, in the ecosystem due to survivability and tolerance the most of microorganisms often change to pathogens and cause severe infections in human beings. Moreover, there is an urgent need for researcher to search for new antimicrobial agents from natural and inorganic substances to eradicate the multi drug resistance bacteria (Kim et al., 1998; Cho, 2005). Recent studies have proved that antibiotics formulated with metal nanocolloids have very effective antibacterial activity and thus nanoparticles-based antimicrobial formulations could be an alternative method for the treatment of multi-drug resistance bacteria (Gade et al., 2008). Our experimental result shows that the AgNPs mediated antibacterial activity can be used as effective growth inhibitors of gram-positive and gram-negative bacteria, making them applicable to diverse medical medicines and antimicrobial control systems.

Chromobacterium violaceum assay was performed with different concentrations $(5,10,15,20 \mu \mathrm{L})$ of AgNPs synthesized from $S$. polyphyllum, by disc diffusion assay using the bioreporter strain CV026. Loss of purple pigment in CV026 cultured with exogenous AHL is indicative of quorum sensing inhibition by seaweeds (Figure 5). A clear halo zone of inhibition around the wells of varying diameter indicates that quorum sensing inhibition effect was relative to the amount of silver nanocolloids added. Finding in this study, confirms for the first time quorum quenching activity of silver nanoparticles produced by the aqueous extracts of seaweeds. Furthermore, to explore quorum quenching potential of AgNPs, further assays were done on inhibition of swarming ability of $P$. aeruginosa. The various concentrations of AgNPs arrest the swarming ability of microbes and maximum inhibition of swarming movement was observed in the plates containing $20 \mu \mathrm{L}$ of AgNPs (Figure 6). Without AgNPs the microbes $P$. aeruginosa freely grow on the whole plate. QS-regulated swarming motility has been characterized as form of flagella-dependent movement on a viscous environment such as semi-solid agar surfaces, while it was regulated by the rhl system in $P$. aeruginosa (Kohler et al., 2000). Therefore, inhibition of P. aeruginosa swarming motility suggests the presence of $r h l$ inhibitor in the AgNPs synthesized from S. Polyphyllum. Our 
study clearly demonstrates that the AgNPs synthesized from marine seaweed exhibits effective antibacterial activity against the selected human pathogens.

\section{Acknowledgement}

The authors are very grateful to the management of SASTRA University and Department of Chemistry and Biosciences for providing facility to carry out our research works.

\section{Reference}

Ahmad A, Mukherjee P, Mandal D, Senapati S, Khan Kumar R, Sastry M. Enzyme mediated extracellular synthesis of Cds nanoparticles by the fungus Fusarium oxysporum. J Am Chem Soc. 2002; 124: 12108-09.

Ahmad AS, Senapati Kham MI, Kumar R, Ramani R, Srinivas $\mathrm{V}$, Sastry M. Intracellular synthesis of gold nanoparticles by a novel alkalotolerant actinomycete, Rhodococcus species. Nanotechnology 2003; 14: 824-28.

Asmathunisha N, Kathiresan K, Anburaj R, Nabeel MA. Synthesis of antimicrobial silver nanoparticles by callus leaf extracts from saltmarsh plant Sesuvium portulacastrum. L Coll Surf B Biointer. 2010; 79: 488-93.

Cho KH, Park JE, Osaka T, Park SG. The study of antimicrobial activity and preservative effects of nanosilver ingredient. Electrochim Acta. 2005; 51: 95.

David LE, Ryan E, Amanda K, Kent S, Dolina VD, Harvey RR, Ian M, Douglas GS. Pseudomonas aeruginosa QuorumSensing Systems may control virulence factor expression in the lungs of patients with cystic fibrosis. Infect Immu. 2002; 70: 1783-90.

Gade AK, Bonde PP, Ingle AP, Marcato P, Duran N, Rai MK. Exploitation of Aspergillus niger for synthesis of silver nanoparticles. J Biobased Mater Bioen. 2008; 2: 243-47.

Gnanadesigan M, Anand M, Ravikumar S, Maruthupandy M, Syed Ali M, Vijayakumar V, Kumaragu AK. Antibac-terial potential of biosynthesised silver nanoparticles using Avicennia marina mangrove plant. Applied Nanaosci. 2012; 2: $143-47$.

Harborne JB. Phytochemical methods: A guide to modern tech nique of plant analysis. London, Champman and Hall, 1998, pp 182-90.

Huang H, Yang XJ. Silver nanoparticles: A review. J Carbohydra Res. 2004; 339: 2627-31.

Jain D, Daima HK, Kachhwana S, Kothari SL. Synthesis of plant mediated silver nanoparticles using papaya fruit extract and evaluation of their antimicrobial activities. J Nanomet Biostr. 2009; 4: 557-63.

Jolocam M, George M, Song HC. Synthesis and characterisation of silver nanoparticles using high electrical charge den- sity and high viscosity organic. Res J Chem Sci. 2011; 1: 1821.

Kim TN, Feng QL, Kim JO, Wu J, Wang H, Chen GL. Antimicrobial effects of metal ions $\left(\mathrm{Ag}^{+}, \mathrm{Cu}^{2+}, \mathrm{Zn}^{2+}\right)$ in hydroxyapatite. J Mater Sci Mater Med. 1998; 9: 129-34.

Klug HP, Alexander LE. X-ray diffraction procedures for polycrystalline and amorphous materials. New York, Wiley, 1954, p 491.

Kohler T, Curty LK, Barja F, Van Delden C, Pechere JC. Swarming of Pseudomonas aeruginosa is dependent on cell-tocell signaling and requires flagella and pili. J Bacteriol. 2000; 182: 5990-96.

Kyung-Hwan C, Jong-Eun P, Tetsuya O, Soo-Gill P. The study of antimicrobial activity and preservative effects of nanosilver ingredient. Electrochimica Acta. 2005; 51: 956-60.

Mcclean, KH. Quorum sensing and Chromobacterium violaceum: exploitation of violacein production and inhibition for the detection of $\mathrm{N}$ - acylchomoserine lactones. Microbiology 1997; 143: 3703-11.

Nikaido H. Multidrug resistance in bacteria. Ann Rev Biochem. 2009; 78: 119-46.

Prasad TNVKV, Elumalai EK. Biofabrication of Ag nanoparticles using Moringa oleifera leaf extract and their antimicrobial activity. Asian Pacific J Trop Biomed. 2011; 1: 439-42.

Rajesh Kumar S, Kannan C, Annadurai G. Synthesis and characterization of antimicrobial silver nanoparticles using marine brown seaweed Padina tetrastromatica. Drug Invention Today 2012; 4: 511-13.

Sharma DNK, Padma P, Khosa RL. Constituent of Tinospora cordifolia root. Fitoterapia LXIX 2009; 6: 541-42.

Shrout JD, Chopp DL, Lust CL, Hentzer M, Givskov M, Parsek MR. The impact of quorum sensing and swarming motility on Pseudomonas aeruginosa biofilm formation is nutritionally conditional. Mol Microbiol. 2006; 62: 5 .

Singh M, Kalaivani R, Manikandan S, Sangeetha N, Kumaraguru AK. Facile green synthesis of variable metallic gold nanoparticle using Padina gymnospora, a brown marine macroalgal. Appl Nanosci. 2013; 2: 145-51.

Smith AM, Duan H, Rhyner MN, Ruan G, Nie SA. A systematic examination of surface coatings on the optical and chemical properties of semiconductor quantum dots. Phys Chem. 2006; 8: 3895-903.

Thirumurugan A, Neethu AT, Jai ganesh R, Gobikrishnan S. Biological reduction of silver nanoparticles using plant leaf extracts and its effect on increased antimicrobial activity against clinically isolated organism. Der Pharma Chemica. 2010; 2: 279-84.

Vattem DA, Mihalik K, Chung DW, Crixell SH, McLean RJC. Quorum sensing modulators of Pseudomonas aeruginosa characterized in Camellia sinensis. Asian J Traditional Med. 2008; 3: 12-23. 